Reprod. Nutr. Dévelop., 1987, 27 (1 B), 291-292.

\title{
Digestion de régimes à base de foin ou d'ensilage de maïs chez le Cheval en croissance
}

W. MARTIN-ROSSET, M. DOREAU (*), P. THIVEND $\left(^{* *}\right)$

Unité Elevage et Alimentation du Cheval.

(*) Laboratoire de la Lactation.

(**) Laboratoire de la Digestion

I.N.R.A., Theix, 63122 Ceyrat, France.

Summary. The digestion of hay or maize silage diets supplemented with the same quantity of concentrate has been studied in young growing heavy horses by investigation of the digestive content collected after slaughter; lignin was used as a marker as the chromic oxide previously employed did not work well. Sixty-two and $64 \%$ of the total apparently digested organic matter was digested before the ileo-caecal valvula, with the hay and silage diets, respectively (starch 85 and $93 \%$, crude protein 41 and $72 \%$ ).

Le rôle des différents compartiments digestifs dans la dégradation des aliments chez le cheval est encore mal connu. C'est pourquoi nous avons étudié, lors de l'abattage de poulains destinés à la boucherie et recevant deux régimes mixtes différant par la nature du fourrage (foin ou ensilage de maïs), la digestion des principaux constituants de la ration et les produits de la fermentation dans les différentes parties du tube digestif.

Matériel et méthodes. Dix poulains de races lourdes $(5$ par régime), âgés de 12 mois, pesant $493 \pm 57 \mathrm{~kg}$, ont été alimentés à volonté avec un régime à base de foin de pré : $29,5 \%$ de cellulose brute $(C B)$ et $7,7 \%$ de matières azotées (MAT) ou d'ensilage de maïs : $20,0 \%$ CB, 26,3\% d'amidon (AMID) et $9,6 \%$ MAT, complémenté avec la même quantité de deux aliments concentrés à base de céréales (avoine-maïs) et de tourteaux (arachide-lin-palmiste) adaptés à chaque fourrage et contenant 31,9\% AMID et 20,3 \% MAT (régime foin), 29,0 \% AMID et $18,9 \%$ MAT (régime ensilage). Les poulains ont consommé $9,06 \mathrm{~kg}$ de matière sèche totale (MST) dans le cas du régime foin et $5,87 \mathrm{~kg}$ MST dans le cas du régime ensilage de maïs, dont $3,70 \mathrm{~kg} \mathrm{MS}$ d'aliment concentré. La composition chimique de la ration totale ingérée est rapportée dans le tableau 1.

TABL. 1. - Composition de la ration totale ingérée (II), digestibilités ileale (II) et totale (III).

\begin{tabular}{|c|c|c|c|c|c|c|c|}
\hline Constituar & nts & $\begin{array}{c}\text { Matière } \\
\text { organique }\end{array}$ & $\begin{array}{l}\text { Matières } \\
\text { azotées } \\
\text { totales }\end{array}$ & $\begin{array}{l}\text { Amidon } \\
\text { (1) }\end{array}$ & $\begin{array}{l}\text { Cellulose } \\
\text { brute }\end{array}$ & $\begin{array}{l}\text { A.D.F. } \\
\text { (2) }\end{array}$ & $\underset{(3)}{\text { Lignine }}$ \\
\hline $\begin{array}{c}\text { Foin } \\
+ \\
\text { Aliment concentré }\end{array}$ & $\begin{array}{r}1 \\
11 \\
111\end{array}$ & $\begin{array}{c}93,1 \pm 0,1 \\
32,3 \\
51,9\end{array}$ & $\begin{array}{c}12,0 \pm 1,0 \\
27,1 \\
65,5\end{array}$ & $\begin{array}{c}13,7 \pm 2,6 \\
83,8 \\
98,3\end{array}$ & $\begin{array}{c}24,1 \pm 1,7 \\
- \\
27,1\end{array}$ & $\begin{array}{c}30,8 \pm 2,2 \\
- \\
26,2\end{array}$ & $\begin{array}{c}4,7 \pm 0,2 \\
- \\
-\end{array}$ \\
\hline $\begin{array}{c}\text { Ensilage de maïs } \\
+ \\
\text { Aliment concentré }\end{array}$ & $\begin{array}{l}\text { I } \\
\text { III }\end{array}$ & $\begin{array}{c}94,3 \pm 0,1 \\
40,0 \\
62,9\end{array}$ & $\begin{array}{c}14,8 \pm 0,9 \\
51,4 \\
71,9\end{array}$ & $\begin{array}{l}27,1 \pm 0,4 \\
92,5 \\
99,0\end{array}$ & $\begin{array}{c}15,0 \pm 0,7 \\
\overline{21,4}\end{array}$ & $\begin{array}{c}20,8 \pm 0,9 \\
- \\
21,3\end{array}$ & $\begin{array}{c}3,6 \pm 0,2 \\
- \\
-\end{array}$ \\
\hline
\end{tabular}

Méthodes : (1) Thivend et al., 1965, (2) Van Soest, 1963. (3) Journet et Jarrige, 1962.

Les poulains ont été abattus $6,12,18,24$ et $30 \mathrm{~h}$ après le dernier repas d'aliment concentré à raison d'un animal par régime et par intervalle de temps. Un échantillon de contenu a été immédiatement prélevé dans 5 compartiments du 
tube digestif ligaturés (tabl. 2). La part des différents constituants de la matière apparemment digestible dans les différents compartiments du tube digestif a été calculée en prenant la lignine (dosée par la méthode de Journet et Jarrige, 1962) comme marqueur (Fonnesbeck, 1968 ; Wolter et al., 1978) ; l'oxyde de chrome distribué sur support de papier Corbett mélangé à l'aliment concentré n'a pas pu être retenu, le transit et le taux de récupération n'étant pas satisfaisants.

TABL. 2. - Poids et répartition des contenus digestifs. Concentration des acides gras volatils dans le tractus digestif.

\begin{tabular}{cccccccc} 
& Régimes & Estomac & $\begin{array}{c}\text { Intestin } \\
\text { grêle }\end{array}$ & Caecum & $\begin{array}{c}\text { Côlon } \\
\text { replié }\end{array}$ & $\begin{array}{c}\text { Colon } \\
\text { flottant } \\
+ \text { rectum }\end{array}$ & $\begin{array}{c}\text { Tube } \\
\text { digestif } \\
\text { total }\end{array}$ \\
\cline { 2 - 8 } & & & & & & &
\end{tabular}

Résultats et discussion. Le poids moyen du contenu digestif total frais a représenté $8,7 \%$ (régime foin) et $7,3 \%$ (régime ensilage) du poids vif des animaux à l'abattage qui était respectivement de 481 et $503 \mathrm{~kg}$ (tabl. 2). Rapporté à la quantité de MS ingérée, le poids sec du contenu total a été considérablement plus élevé avec le régime d'ensilage de maïs $(1,20)$ qu'avec le foin $(0,71)$ ce qui peut indiquer un accroissement du temps de séjour avec la ration riche en amidon. La part de constituants apparemment digestibles qui disparaissent dans l'ensemble estomac + intestin grêle est pour la matière organique, l'amidon et les matières azotées respectivement de 62,85 et $41 \%$ pour le régime foin - concentré et 64,93 et $72 \%$ pour le régime ensilage de maïs - concentré (tabl. 1). En revanche, la digestion dans le caecum semble plus importante pour le régime foinconcentré que pour le régime ensilage de maïs-concentré, comme le confirme la quantité d'AGV (concentration $\times$ volume) dans le caecum plus importante chez les animaux recevant le régime foin - concentré (tabl. 2). La composition du mélange d'AGV n'est cependant pas significativement différente entre les deux régimes.

La digestibilité totale des deux rations mesurées dans le collon flottant + rectum est inférieure de 7 à 10 points à celles mesurées par collecte totale pour des régimes comparables chez le cheval adulte, sans doute en raison de la méthode de mesure et des aptitudes limitées du jeune cheval en croissance à digérer les parois végétales. Les digestibilités partielles mesurées, dans l'ensemble estomac + intestin grêle en particulier, sont du même ordre que celles rapportées dans la bibliographie (cf. INRA, 1984). La lignine $n^{\prime}$ est toutefois pas un bon marqueur en raison de l'imprécision du dosage d'une part, et des taux de récupération très variables que nous avons enregistrés d'autre part (60 à $119 \%$ ).

INRA, 1984. Le Cheval. In R. Jarrige et W. Martin-Rosset. Ed. INRA Publications. Route de St-Cyr, 78000 Versailles, p. 689.

Fonnesbeck P. V., 1968. J. anim. Sci, 27, 1336-1344.

Journet M., Jarrige R., 1962. Ann. Biol. anim. Bioch. Biophys., 2, 223-250.

Thivend P., Guilbot A., Mercier C., 1965. Ann. Biol. anim. Bioch. Biophys., 5, 513-526.

Van Soest P. J., 1963. J. Assoc. Off. An. Chem., 46, 829-835.

Wolter R., Gouy D., Durix A., Letourneau J. C., Carcelen M., Landreau J., 1978. Ann. Zootech., 27, 47-60. 